\title{
PROTEÇÃO E BEM-ESTAR NA ESCOLA: UM EMARANHADO DE NÓS PARA DESATAR EM CONTEXTOS PÓS-PANDÊMICOS
}

\section{PROTECTION AND WELFARE AT SCHOOL: A TANGLE OF KNOTS TO UNTIE IN POST-PANDEMIC SCENARIOS}

\author{
Luciene Regina Paulino Tognetta ${ }^{1}$ \\ Universidade Estadual Paulista (UNESP), Araraquara, SP, Brasil \\ Talita Bueno Salati Lahr ${ }^{2}$ \\ Universidade Estadual Paulista (UNESP), Araraquara, SP, Brasil
}

\begin{abstract}
Resumo: $\mathrm{O}$ contexto pandêmico tem despertado reflexões acerca das lacunas na proteção de crianças e adolescentes em nosso país. Os problemas já existiam, mas foram potencializados e escancarados com a crise humanitária que vive o Brasil. As consequências dos problemas relacionados ao sofrimento emocional, aos riscos aos quais são submetidos crianças e adolescentes diante de violações de direitos, cyberagressões e situações de violência doméstica tornam as instituições que atendem esse público, em especial, a escola, os únicos locais que representam proteção e segurança para falar de sentimentos, problemas e medos vivenciados por eles. Assim, a formação dos profissionais que ali atuam torna-se fundamental. Além do que, um alerta deve ser feito: a escola precisará estar atenta a tais demandas no retorno das atividades presenciais ou se tornará, em breve, palco de novas tragédias por representar a convivência não cuidada e a proteção não garantida a crianças e adolescentes vulneráveis.
\end{abstract}

Palavras-chave: Rede de proteção; pandemia; escola; violência; sofrimento emocional.

\begin{abstract}
The pandemic scenario has been raising reflections about gaps in protection of children and teenagers in our country. The problems already existed but were potentialized and wide opened with the humanitarian crisis that Brazil faces. The consequences of the problems related to emotional suffering, the risks by which children and teenagers were submitted, facing the violence of their rights, cyber aggressions and domestic violence scenarios, turn the institutions that attend this public, especially the schools, the single places that represent protection and safety to talk about feelings, problems and fears faced by them. Therefore, training teachers that work there becomes vital. Besides, an alert must come up: the school is going to need to be alert to such claims when the in-person classes come back or it may become stage for new tragedies soon, for representing the uncared coexistence and the protection didn't guaranteed to vulnerable children and teenagers.
\end{abstract}

Keywords: Social protection; pandemic; school; violence; emotional suffering.

\section{Uma sociedade com a 'corda no pescoço'}

\footnotetext{
${ }^{1}$ Doutora em Psicologia Escolar e do Desenvolvimento Humano pela Universidade de São Paulo (USP), professora do Departamento de Psicologia da Educação da Faculdade de Ciências e Letras e do Programa de Pós Graduação em Educação Escolar da Universidade Estadual Paulista Júlio de Mesquita Filho (UNESP) - Campus de Araraquara. EMAIL: luciene.tognetta@unesp.br. ORCID: http://orcid.org/0000-0003-0929-4925

2 Mestranda do Programa de Pós-Graduação em Educação Escolar da Universidade Estadual Paulista Júlio de Mesquita Filho (UNESP). E-MAIL: talitabslahr@gmail.com. ORCID: https://orcid.org/0000-0003-2917-324X

Revista Tópicos Educacionais, Pernambuco, v. 27, n. 01, p. 62-78, 2021. ISSN: 2448-0215. https://periodicos.ufpe.br/revistas/topicoseducacionais/index Dossiê "Conflitos, violências, bullying na escola: problemas da convivência potencializado pela pandemia?" DOI: 10.51359/2448-0215.2021.250506
} 
O Art. $4^{\circ}$ do Estatuto da Criança e do Adolescente (BRASIL, 1990) é explícito ao responsabilizar a família, a comunidade, o poder público e a sociedade em geral para a garantia dos direitos fundamentais de crianças e adolescentes enquanto prioridade absoluta. Da mesma forma, a Lei $\mathrm{n}^{\mathrm{o}}$ 13.431/2017 é promulgada com a finalidade de reforçar a organização do Sistema de Garantia de Direitos (SGD), especialmente para crianças e adolescentes vítimas ou testemunhas de violência (BRASIL, 2017). Ambas as legislações enfatizam a responsabilidade da sociedade e dos diferentes atores da rede de proteção frente às situações de violência envolvendo crianças e adolescentes.

Ora, mas por que será tão necessário reforçar a importância do envolvimento da sociedade na proteção de crianças e adolescentes? Não seria óbvio que os adultos deveriam proteger os pequenos? Não é aleatória a distinção da proteção para aqueles que são ainda "candidatos à humanidade"- tomando a expressão de Arendt para falar das crianças e adolescentes que são humanizados pelo próprio homem (ARENDT, 2007, p.102). A garantia para que esses pequenos humanos tenham dignidade em seu desenvolvimento é conquista de um marco civilizatório construído pela própria humanidade e que, infelizmente, como outros marcos que defendem direitos dos que são "diferentes" - mulheres, negros, pobres - tem sido rechaçado em razão da falta de equacionamento e sensibilidade moral presentes em tempos atuais.

Certamente, a exposição à violência de crianças e adolescentes não é condição recente. Contudo, várias foram as conquistas afirmadas por esses marcos aos quais nos referimos. Para se ter uma ideia, o sistema de denúncias, no Brasil, foi organizado por meio do "Disque 100" em 1997 por organizações não governamentais passando a ser de responsabilidade do governo federal em 2003. Refere-se a um canal para identificação de violências aos direitos humanos que visa a comunicação entre a sociedade civil e poder público e que favorece, por meio do estudo de seus dados, a orientação e elaboração de políticas públicas.

Dados do Datasus ${ }^{3}$ indicam que em 2017, de 307.367 vítimas de violência no Brasil, 126.230 eram crianças e adolescentes, ou seja, $41 \%$ daqueles que são vitimizados e que, de alguma forma, tornam-se estatísticas no sistema de saúde, são crianças e adolescentes. Em 2018, um ano depois, o Disque 100, canal de denúncias do Ministério da Mulher, da Família e dos Direitos Humanos, registrou 152.178 denúncias de violações contra esse público no país. Tais dados nos

3

https://www.correiobraziliense.com.br/app/noticia/cidades/2019/09/09/interna cidadesdf,781448/criancas-e-adolescentes-saoalvo-de-varios-tipos-de-violencia.shtml

Revista Tópicos Educacionais, Pernambuco, v. 27, n. 01, p. 62-78, 2021. ISSN: 2448-0215. https://periodicos.ufpe.br/revistas/topicoseducacionais/index

Dossiê "Conflitos, violências, bullying na escola: problemas da convivência potencializado pela pandemia?" DOI: $10.51359 / 2448-0215.2021 .250506$ 
evidenciam um problema que não é apenas de crianças e adolescentes, mas de toda a família cuja vulnerabilidade é presente, como continuaremos a apontar a seguir.

Em 2018, foram notificados 32.780 casos de violência e exploração sexual de meninos e meninas menores de 19 anos, tendo maior prevalência as violações em relação às crianças e adolescentes do sexo feminino (85,5\%) e entre pessoas negras $(56,5 \%)$, o que evidencia questões importantes de raça e gênero. No ano de 2019, 45,5 mil homicídios foram notificados pelo Sistema de Informações sobre Mortalidade (SIM), sendo 7,1 mil cometidos contra crianças e adolescentes entre 0 a 19 anos e 75,5\% por armas de fogo (FUNDAÇÃO ABRINQ, 2021).

Contudo, diante desses números, há um fato curioso quando nos deparamos com os dados que mostram tais problemas a partir de 2020. Em meio a todo o contexto de pandemia, isolamento social e interrupção das aulas presenciais, é interessante notar que os números de denúncias de violência contra crianças e adolescentes e pedidos de ajuda despencaram. Vejamos o exemplo dos atendimentos realizados pela SAFERNET sobre denúncias ou pedidos de ajuda, relacionados a saúde mental ou bem-estar, como ideações suicidas, automutilações e outros tipos de sofrimento emocional: quando fazemos uma análise desses pedidos por perfil etário, contando com os meios de comunicação via e-mail e chat, em 2019, a SAFERNET registrou 2188 atendimentos a crianças e adolescentes e em 2020 o registro foi apenas de 401. Ainda discutiremos as possíveis explicações para esses fatos em especial.

No estado de Santa Catarina as denúncias acerca da violência contra crianças e adolescentes diminuíram em 53,3\% (PLATT, GUEDERT, COELHO, 2021) e, no estado do Rio Grande do Sul, em 54\% (LEVANDOWSKI et al, 2021). Tais informações confirmam a dificuldade de pessoas que se encontram em situação de risco identificarem instituições seguras e confiáveis para a realização de denúncias neste período.

Ao considerarmos que a grande maioria das violações ocorre dentro de casa $(62,3 \%$ das violações denunciadas ocorreram na casa da criança / adolescente ou na casa da família, segundo dados do Disque 100 de 2019), a falta da escola, local de segurança, convivência e vínculos de confiança faz com que crianças e adolescentes não tenham pessoas de fora de seu círculo familiar para relatar os problemas enfrentados e se sintam ainda mais sozinhos e desprotegidos.

O fato é que as investigações que têm sido conduzidas e que ainda estão por vir sobre as questões de convivência experimentadas, nestes tempos, por crianças e adolescentes só indicam e ainda indicarão o que instituições de proteção à infância previram, no início da pandemia pela

Revista Tópicos Educacionais, Pernambuco, v. 27, n. 01, p. 62-78, 2021. ISSN: 2448-0215. https://periodicos.ufpe.br/revistas/topicoseducacionais/index Dossiê "Conflitos, violências, bullying na escola: problemas da convivência potencializado pela pandemia?" DOI: 10.51359/2448-0215.2021.250506 
COVID-19: muitos serão os danos gerados pelo isolamento social e pelo fechamento de serviços que visam ao atendimento desse público. A nota técnica do The Alliance for Child Protection in Humanitarian Action (2020) intitulada "COVID-19: proteção de crianças contra a violência, o abuso e a negligência no lar" enfatizou que os fatores que poderiam agravar ou gerar situações de risco para crianças e adolescentes no período de isolamento social e pandêmico envolvem o aumento da pobreza e da insegurança alimentar; a impossibilidade de acesso de crianças e adolescentes à educação, presencialmente ou de forma online; o aumento no acesso à internet e diminuição do monitoramento dos responsáveis, o que os expõe a maior risco; a ausência de refeições antes oferecidas pela escola e outras instituições sociais; a paralisação dos serviços da rede de proteção e apoio a crianças, adolescentes e suas famílias; a interrupção da rotina das crianças e de seus cuidadores; e o aumento do consumo de álcool e substâncias psicoativas pelos adolescentes e cuidadores. A nota previa que tais fatores poderiam, inclusive, aumentar a possibilidade de pais e responsáveis se tornarem violentos ou abusivos em decorrência do aumento do estresse vivido no contexto pandêmico.

Dados de pesquisas recentes corroboram a previsão realizada. O que ocorre é que a pandemia potencializou problemas que já existiam em nosso país há muito tempo. Um fator de risco que pode intensificar o problema da violência em geral é a pobreza. Pessoas em pobreza extrema têm seus medos, desânimos, angústias, tristezas e preocupações aumentados. Antes da pandemia, os dados de uma amostra do $\mathrm{IBGE}^{4}$ mostravam uma estimativa de 170 mil pessoas ingressando na extrema pobreza em 2019, ou seja, 13,8 milhões de pessoas, o que equivale a $6,7 \%$ da população brasileira vivendo com menos de 1,90 dólar por dia. Durante a pandemia, vimos o desemprego aumentar, chegando a 14,1 milhão de desempregados, o que representa um crescimento de 1,6 milhão de pessoas sem ocupação, de 2020 para $2021^{5}$. Por sua vez, o desemprego está diretamente correlacionado à vulnerabilidade social. Se o Brasil já tinha um alto número de pessoas vivendo na miséria, com deficiências importantes em seus direitos humanos básicos como saúde, moradia, alimentação e saneamento básico, teve suas fragilidades aumentadas e expostas, ferindo ainda mais a dignidade de seu povo no contexto pandêmico. O que diremos, então, dos seus "pequenos"!

\footnotetext{
${ }^{4}$ https://censo2021.ibge.gov.br/2012-agencia-de-noticias/noticias/25882-extrema-pobreza-atinge

5 https://economia.uol.com.br/empregos-e-carreiras/noticias/redacao/2021/01/28/pnad-continua---desemprego--novembro.htm

Revista Tópicos Educacionais, Pernambuco, v. 27, n. 01, p. 62-78, 2021. ISSN: 2448-0215. https://periodicos.ufpe.br/revistas/topicoseducacionais/index

Dossiê "Conflitos, violências, bullying na escola: problemas da convivência potencializado pela pandemia?" DOI: $10.51359 / 2448-0215.2021 .250506$
} 
A Declaração dos Direitos da Criança, aprovada pelas Nações Unidas em 1959, enfatizava em seu princípio IV que a "criança terá direito a desfrutar de alimentação, moradia, lazer e serviços médicos adequados". Entretanto, 60 anos se passaram e, ainda, ao analisar brevemente a situação atual da criança e do adolescente no Brasil, pode-se observar dados que geram indignação. Em 2019, parte dos 45\% de crianças e adolescentes que vivem com menos de meio salário mínimo per capita moravam em casas construídas com materiais não duráveis, sem banheiro exclusivo para a residência e com alta densidade de pessoas no mesmo espaço (3 ou mais no mesmo dormitório); $13,5 \%$ das crianças de até 5 anos viviam em situação de desnutrição ao considerar os indicadores de altura e idade e 40,6\% da população brasileira vivia sem acesso a coleta de esgotos e saneamento básico, porcentagem que equivale a mais de 85 milhões de pessoas. Esses dados evidenciam condições menos favoráveis e com menos acesso aos direitos fundamentais nas regiões Norte e Nordeste do país, mas também mostram as vulnerabilidades de regiões mais desenvolvidas, como a região sudeste que, apesar de melhores condições de saneamento básico, ainda possui $28,4 \%$ de sua população sem acesso a esse serviço fundamental (ABRINQ, 2021).

O que esses dados nos mostram? As pesquisas indicam claramente as diferenças e injustiças sociais presentes em nosso país e, mais do que isso, a falta de políticas públicas adequadas e que deem conta da integridade do povo brasileiro e de seus filhos e filhas que apesar de contarem com um estatuto que defende seus direitos há mais de 30 anos, ainda apresenta falhas significativas na dita proteção integral, na prioridade absoluta e na efetivação de políticas públicas.

É fato que para um desenvolvimento saudável, crianças e adolescentes precisam de afeto, cuidado, proteção e acesso a condições mínimas de subsistência. Precisam de uma casa, de roupas que as protejam do frio, de alimentos suficientes que favoreçam seu crescimento saudável e de pessoas que atendam às suas necessidades e as protejam. Dallari (1986) diria que apenas os cegos morais não são capazes de perceber que essas são as necessidades de todas as crianças e não apenas das "suas crianças". Fazemos nossas as palavras do autor quando afirma que cada pessoa que não reage à falta de acesso de crianças e adolescentes a condições mínimas de sobrevivência, é também um de seus agressores.

A mesma declaração de 1959 pressupunha em seu Princípio VII que toda criança teria acesso à educação escolar em "condições de igualdade de oportunidades", o que é, atualmente,

Revista Tópicos Educacionais, Pernambuco, v. 27, n. 01, p. 62-78, 2021. ISSN: 2448-0215. https://periodicos.ufpe.br/revistas/topicoseducacionais/index Dossiê "Conflitos, violências, bullying na escola: problemas da convivência potencializado pela pandemia?" DOI: $10.51359 / 2448-0215.2021 .250506$ 
diante das diferenças sociais e de oportunidades entre crianças e adolescentes que estudam em colégios particulares e escolas públicas, um grande abismo.

O relatório da Fundação Abrinq "Cenário da Infância e Adolescência no Brasil em 2021", organizado com base nos dados da Pesquisa Nacional por Amostra de Domicílios - módulo COVID (PNAD COVID) realizada pelo IBGE e pelo Ministério da Saúde apresenta estatísticas importantes referentes aos meses de julho a novembro de 2020 sobre as vulnerabilidades envolvendo a infância no contexto da pandemia da COVID-19 em nosso país. Nesse período, $6,5 \%$ das crianças e adolescentes informaram não estar estudando, ou seja, em média 1,66 milhão de pessoas de até 17 anos estavam fora das escolas ou sem ser atendidos pelas ações dessas instituições já que o contexto era de isolamento social. Essa porcentagem é ainda maior para os beneficiários do Bolsa Família. Aliás, sobre o atendimento escolar neste contexto, aproximadamente 4,6 milhões de crianças e adolescentes (19\% dessa população) relataram não ter recebido as atividades escolares para serem realizadas em casa. Das crianças e adolescentes até 17 anos que vivem com uma renda familiar de menos de meio salário mínimo per capita (em torno de $45 \%$ dessa população, segundo dados de 2019), 27,3\% não possuem nenhum acesso à internet através de qualquer equipamento, o que prejudica por completo o acesso às atividades escolares em meio à pandemia da COVID-19 e torna ainda mais evidente a desigualdade de acesso a oportunidades pela via da educação.

Ainda em relação às escolas, em 2020, 8,6 mil escolas informaram não ter acesso a coleta de esgotos, 3,8 mil escolas relataram não ter energia elétrica e 3,4 mil escolas não possuíam nenhuma distribuição de água (ABRINQ, 2021). Dados alarmantes para um país já abatido pela desesperança...

E em seu Princípio IX, a Declaração dos Direitos da Criança evidencia que "a criança deve ser protegida contra toda forma de abandono, crueldade e exploração". O que dizer dos assassinatos recentes de crianças como o menino Henri ${ }^{6}$ que morreu por meio da violência física ou da negligência daqueles que deveriam, em primeira instância protegê-las, os próprios genitores? Violência grave, fatal e de caráter desumano já que violentar uma criança é desconsiderá-la enquanto ser humano e desrespeitar o seu direito de ser (DALLARI, 1986). É fato que a Declaração dos Direitos da Criança mesmo estando em vigor desde 1959 e o Estatuto da Criança e

\footnotetext{
${ }^{6}$ https://veja.abril.com.br/brasil/alem-da-morte-de-henry-dr-jairinho-vai-responder-por-tortura-de-criancas/
}

Revista Tópicos Educacionais, Pernambuco, v. 27, n. 01, p. 62-78, 2021. ISSN: 2448-0215. https://periodicos.ufpe.br/revistas/topicoseducacionais/index Dossiê "Conflitos, violências, bullying na escola: problemas da convivência potencializado pela pandemia?" DOI: $10.51359 / 2448-0215.2021 .250506$ 
do Adolescente desde 1990, infelizmente, não têm garantido a dignidade das crianças e adolescentes brasileiros. No decorrer destes 30 anos, outras legislações foram sendo formuladas, compondo e alterando o ECA, a fim de fortalecer a legislação e garantir sua efetividade. É o caso da Lei 13.010/2014, promulgada após a morte do menino Bernardo, dando nome à legislação que alterou o artigo 18 do ECA e descreveu o que seriam os "castigos físicos" e o "tratamento cruel ou degradante" assim como determinou medidas a serem aplicadas aos pais ou qualquer cidadão que venha descumprir ou violentar crianças e adolescentes.

Da mesma forma, a Lei 13.431/2017, conhecida popularmente como a Lei da Escuta Especializada, foi sancionada com o objetivo de organizar e fortalecer o Sistema de Garantia de Direitos no âmbito da violência contra crianças e adolescentes ${ }^{7}$. A implementação dessa lei passa a exigir um aperfeiçoamento das ações dos atores da rede de proteção e dos serviços existentes, assim como uma sistematização ou, em alguns municípios, a construção de fluxos e/ou protocolos com o objetivo de aprimorar o atendimento às vítimas de violência, evitar a revitimização de crianças e adolescentes e favorecer a responsabilização de seus agressores.

Tais atores ou serviços da rede de proteção são, então, chamados a dialogar, romper com as amarras do serviço setorializado e se reconstruir enquanto rede a fim de garantir, de fato, a proteção às vítimas ou testemunhas de violência. Segundo Pereira e Teixeira (2013), para que o fortalecimento dessa rede ocorra é necessário haver articulação entre esses serviços e a consolidação do trabalho intersetorial.

Isto posto, torna-se importante reforçar a responsabilidade compartilhada de toda a sociedade sobre a proteção de meninos e meninas e isso inclui aquele organismo fundamental da Rede de Proteção cuja ausência reclamamos nesta pandemia: a escola. Assim, seguimos com dois pontos fundamentais visando à tal proteção: a importância da organização e formação das equipes escolares na retomada das atividades presenciais, a fim de que o cuidado e o bem-estar de crianças e adolescentes sejam uma prioridade e a necessária articulação da rede de proteção para a eficácia deste atendimento.

\footnotetext{
${ }^{7}$ Cabe ressaltar aqui que o Sistema de Garantia de Direitos, evidenciado por meio da Resolução CONANDA No 113 , de 19 de abril de 2006, já possui sua organização, entretanto envolve a garantia de todos os direitos fundamentais. Já a Lei 13.431/2017 e o Decreto 9.063/2018 vem caracterizar e nortear esse Sistema a problemas mais específicos, componentes do direito ao respeito e à dignidade, que concerne aos tipos de violência cometidas contra crianças e adolescentes.

Revista Tópicos Educacionais, Pernambuco, v. 27, n. 01, p. 62-78, 2021. ISSN: 2448-0215. https://periodicos.ufpe.br/revistas/topicoseducacionais/index Dossiê "Conflitos, violências, bullying na escola: problemas da convivência potencializado pela pandemia?" DOI: 10.51359/2448-0215.2021.250506
} 


\section{Revista Tópicos Educacionais}

\section{Os nós que nos apertam: problemas atuais ou problemas de sempre?}

O tema da "saúde mental" nunca esteve tão presente nos noticiários e pesquisas acadêmicas. Pesquisa realizada pela Fiocruz ${ }^{8}$ indicou um aumento de $90 \%$ nos casos de depressão entre março e abril de 2020 e o dobro de casos de pessoas relatando sintomas de ansiedade e estresse no mesmo período. Outro estudo realizado por Barros et al (2020) com 45.161 brasileiros verificou que, durante o período de isolamento social, 40,4\% dos respondentes se sentiram frequentemente tristes ou deprimidos, $52,6 \%$ se sentiram ansiosos ou nervosos e $43,5 \%$ relataram início de problemas para dormir.

A pandemia evidenciou problemas já antes enfrentados em lares brasileiros, porém intensificados pela fragilidade das políticas públicas de nosso país. Famílias que já apresentavam dificuldades em lidar com demandas de uma sociedade pós-moderna, permeada por relações líquidas e passageiras, sem vínculos fortalecidos (BAUMAN, 2001), passaram a ter de enfrentar também problemas de convivência virtual por parte de seus filhos na internet, acompanhar o uso de plataformas digitais e observar possíveis comportamentos autodestrutivos.

Certamente, as preocupações do mundo adulto são grandes diante de um cenário de desemprego, falta de comida, falta de vacinas e tantas outras ausências. Como "homens feitos", conseguimos antecipar e compreender a dimensão que toma um momento de crise humanitária como o que estamos vivenciando. Contudo, isso não significa que crianças e adolescentes também não se sintam acuadas, preocupadas, angustiadas, entediadas, com ansiedades, depressões, solidão e tantos outros problemas que podem ser chamados de saúde mental. Há um equívoco entre nós cada vez que olhamos para as crianças que se comportam de maneira inusitada, com as birras, choros, silêncios, insultos e outros comportamentos que, como adultos, julgamos serem decorrentes muito mais da desobediência, do desinteresse e mesmo de descaso da criança e do adolescente. Não imaginamos o quanto esses comportamentos podem ser formas de manifestar algo muito ruim para ser tolerado: a angústia, a tristeza, a ansiedade, o medo.

Quando expressam suas emoções ou sentimentos (ou não as expressam, o que passa a ser o problema) crianças e adolescentes também sinalizam suas dificuldades no relacionamento consigo mesmas e com os outros. Ocorre que a desorganização dos núcleos familiares e a dificuldade em lidar com estas demandas geram ainda maior desproteção. Por vezes, como pais ou

\footnotetext{
${ }^{8}$ https://www.fiocruzbrasilia.fiocruz.br/depressao-ansiedade-e-estresse-aumentam-durante-a-pandemia/

Revista Tópicos Educacionais, Pernambuco, v. 27, n. 01, p. 62-78, 2021. ISSN: 2448-0215. https://periodicos.ufpe.br/revistas/topicoseducacionais/index

Dossiê "Conflitos, violências, bullying na escola: problemas da convivência potencializado pela pandemia?" DOI: $10.51359 / 2448-0215.2021 .250506$
} 
responsáveis, não sabemos o que fazer com os filhos e com seus sofrimentos, desconhecemos formas mais assertivas de falar sobre seus sentimentos e de transformar, em palavras, toda angústia, medo e insegurança diante de um contexto tão novo. Infelizmente, essa dificuldade de diálogo e o desconhecimento de uma forma mais equilibrada de educação das crianças e adolescentes pode levar a atitudes mais agressivas de seus cuidadores, caso não tenham o suporte e o manejo adequado para reconhecer tais sentimentos e auxiliá-los a lidar com tamanha angústia.

O fato é que, para além de todas essas questões, uma preocupação demasiadamente academicista acaba surgindo entre nós quando se impõe o debate sobre a quem cabe a responsabilidade quanto a essa questão - às instituições que cuidam da saúde, à família ou à escola? Mas como separamos as responsabilidades destas instituições que cuidam do mesmo fenômeno - o humano? Mais do que a preocupação em nomear como "Saúde mental" ou "problemas emocionais" como frequentemente chamamos na Psicologia ou na Educação, a escola não está isenta do cuidado com as formas pelas quais crianças e adolescentes expressam aquilo que sentem e terão, para além do trabalho com os alunos e alunas, que acolher as famílias cuja especialidade não é a pesquisa sobre as formas mais evoluídas de educação de uma criança. Uma pesquisa americana da Kaiser Family Foundation ${ }^{9}$ nos EUA, realizada em março de 2021 apontou que $46 \%$ dos adultos, pais de crianças e adolescentes menores de 18 anos, sentem que a pandemia tem um impacto negativo sobre a sua saúde mental, ou seja, os adultos das famílias, também precisarão de apoio já que podem não ser capazes de, sozinhos, ajudar seus filhos a superarem os problemas que enfrentarão.

Onde estarão as crianças e adolescentes passada a pandemia? Certamente, o lugar que, ao menos, esperamos que estejam, será nas escolas.

Quando falamos anteriormente dos atendimentos a crianças e adolescentes pela SAFERNET afirmando que seus registros diminuíram abruptamente entre 2019 e 2020, prometemos e ficamos devedoras de possíveis explicações para tanto. $\mathrm{O}$ fato é que as violências não diminuíram, mas a instituição que mais identifica situações de violência e orienta ou ensina o adolescente a procurar os canais de denúncia e a pedir ajuda estava "fechada" ou distante de meninos e meninas que precisam, ainda mais, de proteção, neste momento. É a escola que tem essa responsabilidade, é a escola que tem essa importância.

\footnotetext{
9 https://www.kff.org/coronavirus-covid-19/

Revista Tópicos Educacionais, Pernambuco, v. 27, n. 01, p. 62-78, 2021. ISSN: 2448-0215. https://periodicos.ufpe.br/revistas/topicoseducacionais/index Dossiê "Conflitos, violências, bullying na escola: problemas da convivência potencializado pela pandemia?" DOI: $10.51359 / 2448-0215.2021 .250506$
} 
Neste momento, em que essas relações entre a instituição escolar e os alunos estão tão fragilizadas, crianças e adolescentes encontram-se à deriva, à própria sorte. Consequentemente, este é o panorama com o qual as escolas irão se deparar no retorno às atividades presenciais, somando aos problemas de antes, os atuais: as vulnerabilidades já existentes antes da pandemia e as demandas geradas pela doença COVID-19, como o luto, as perdas, o medo, problemas de ordem emocional e a violência doméstica. E quem poderá ajudar? Qual instituição, senão a própria escola que estará diariamente com meninos, meninas e famílias tentando preencher as lacunas que ficaram em meio a este quase um ano e meio de isolamento e distanciamento na convivência e nas relações?

Está posto, portanto, a importância da instituição escolar e da preparação de seus adultos para acolherem e transformarem os espaços de convivência em seu interior em oportunidades de diálogo, de acolhida, de escuta e de ajuda. Contudo, acreditar que em meio a tantos problemas que eclodirão nesta instituição, a escola poderá, sozinha, contornar uma situação tão adversa, será ingenuidade de nossa parte. Problemas de saúde mental por decorrência ou como denúncia das agressões domésticas, dos abusos psicológicos e físicos sofridos precisarão, certamente, ser compartilhados com outros organismos que compõem, juntamente com a escola, a Rede de Proteção.

Será preciso que os órgãos de defesa de direitos como o Conselho Tutelar, o Ministério Público e as Delegacias de Polícia atendam e encaminhem as situações de violência e violações de direitos, inclusive no âmbito do acompanhamento jurídico.

O fato é que, mais do que nunca, será imprescindível que outras políticas de atendimento como a Assistência Social, a Saúde, a Habitação, entre outras, atuem com as famílias a fim de garantir a proteção e a dignidade de crianças, adolescentes e adultos. Da mesma forma, acionar Conselhos de Direitos e outros órgãos de controle será uma condição sine-qua-non para aqueles que pretendem afirmar a dignidade dos pequenos humanos em desenvolvimento.

\section{Quem desata ou pode desatar os nós?}

Por diversas vezes ouvimos profissionais da rede de escolas públicas e particulares se referirem à rede de proteção como "rede de apoio" e ao questionarmos a quem estavam se referindo, mencionaram o Conselho Tutelar, em especial, mas também outras políticas de Revista Tópicos Educacionais, Pernambuco, v. 27, n. 01, p. 62-78, 2021. ISSN: 2448-0215. https://periodicos.ufpe.br/revistas/topicoseducacionais/index Dossiê "Conflitos, violências, bullying na escola: problemas da convivência potencializado pela pandemia?" DOI: $10.51359 / 2448-0215.2021 .250506$ 
atendimento, como a Assistência Social. Ao se referir aos serviços e atores desta rede que tem por objetivo maior a proteção de crianças e adolescentes, sempre iremos nos referir à Rede de Proteção em que também a escola está inserida. Não se trata, portanto, de uma obrigação delimitada a todos os outros organismos de apoiar a escola, e sim, de um conjunto em que os diferentes organismos que compõem uma rede compartilham do mesmo objetivo que é a garantia da proteção e o bem-estar daqueles que ainda estão em processo de humanização, como dissemos antes. A escola é um desses organismos e portanto, corresponsável pela articulação entre todos.

Digamos que seja até compreensível que aqueles que estejam no dia a dia da escola desconheçam esse sistema tão necessário à promoção dos direitos da criança e do adolescente do qual a escola faz parte. Contudo, o que temos visto em diferentes redes de ensino, quer sejam municipais ou estaduais, é que este desconhecimento se dá, o que é muito mais sério, em decorrência da não participação da escola em discussões intersetoriais e Conselhos de Direitos nos quais devem ser elaborados fluxos de atendimentos e discutidas as ações de amparo, proteção, cuidado e formação de nossos pequenos.

Há, portanto, um grande nó ainda para se desatar neste país em que pouco se constata a participação democrática nas instâncias públicas ${ }^{10}$. Quando nos deparamos com a participação efetiva nos conselhos em que as políticas públicas são pensadas, controladas ou efetivadas, quase não há representantes da educação, no seu sentido mais pleno (aqueles que sabem dos problemas e situações que atingem a comunidade educativa e que atuam diretamente com os problemas e situações de violência vivenciados na escola).

Entretanto, é conhecida também a ineficiência e as falhas dessa rede que deveria atuar de forma protetiva, mas que geralmente encontra-se diante da "política do encaminhamento", na qual se preenchem papéis, cumpre-se com a burocracia e encaminham-se os casos para diferentes serviços, mas poucos são os atendimentos; esporádicos são os acompanhamentos e raras às vezes em que a escuta acontece, de fato, com as famílias, crianças e adolescentes que precisam de ajuda.

Tais reclamações e a falta de credibilidade em relação às ações da Rede de Proteção são comuns tanto nas escolas quanto nos demais serviços. Segundo Silva e Alberto (2019), o fato de as políticas públicas da infância e adolescência trabalharem de forma desarticulada, com pouca

\footnotetext{
${ }^{10}$ Talvez pelo fato de que em países como o Brasil não se veja a diferença entre o pensamento político e a profissão de político para a qual, quem se candidata, em grande parte das vezes, visa subsidiar grupos privilegiados ou cumprir uma tradição familiar que não se distingue de um colonialismo histórico.

Revista Tópicos Educacionais, Pernambuco, v. 27, n. 01, p. 62-78, 2021. ISSN: 2448-0215. https://periodicos.ufpe.br/revistas/topicoseducacionais/index Dossiê "Conflitos, violências, bullying na escola: problemas da convivência potencializado pela pandemia?" DOI: 10.51359/2448-0215.2021.250506
} 
qualificação e grande rotatividade de seus profissionais causa graves prejuízos na garantia de direitos assegurados pela legislação.

Isso posto, há um enorme abismo a superar: professores relatam se sentir sozinhos e abandonados quando não têm a integralidade dessa rede funcionando; famílias se sentem perdidas, com seus direitos não atendidos e crianças e adolescentes perambulam por todos esses serviços em vão, sem o cuidado que deveriam receber.

\section{Desatando os nós}

Desde 2015, no Brasil, temos leis que garantem o direito das crianças e adolescentes à aprendizagem da convivência. A Lei Antibullying, que mais recentemente foi incorporada à Lei de Diretrizes e Bases da Educação, confirma a necessidade de se estabelecer uma "cultura da paz" nas escolas: se há cultura, há continuidade, há processo e não uma atividade pontual. O que sustenta a lei são, na verdade, os resultados de diferentes investigações que têm mostrado que os problemas de violência na escola só são efetivamente superados quando se tem um programa estruturado, intencional, coordenado entre professores, alunos e toda a comunidade educativa.

Da mesma forma, o que nossas investigações no Brasil têm mostrado é que a atuação bomberística nas escolas é o instrumento mais utilizado ainda para vencer os problemas que afligem o cotidiano escolar. Por vezes, conter as chamas é mais do que necessário, mas não se atua, infelizmente, nas causas do problema. Temos insistido que um problema tão complexo como o bullying, por exemplo, e aqueles que enfrentaremos na volta da pandemia relacionados aos sofrimentos emocionais não são questões simples de resolver. São problemas complexos que exigem de nós, primeiramente, o reconhecimento de que atuar preventivamente é condição.

Como se resolve o problema de meninos e meninas que desejam explodir a escola, que escolhem a escola como alvos de suas angústias vividas e que atentam contra a vida, como fez o garoto de uma pacata cidade do interior catarinense que matou, desumanamente, crianças pequenas e professores ${ }^{11}$ ? Não se resolve.

Não se resolve porque a intervenção é pouco eficaz em casos como esses. Então, como se previne se a escola atacada nem era aquela em que o agressor frequentava? Investindo na

11 https://www.cnnbrasil.com.br/nacional/2021/05/04/autor-dos-crimes-em-escola-primaria-de-sc-sofria-bullying-emaltratava-animais

Revista Tópicos Educacionais, Pernambuco, v. 27, n. 01, p. 62-78, 2021. ISSN: 2448-0215. https://periodicos.ufpe.br/revistas/topicoseducacionais/index

Dossiê "Conflitos, violências, bullying na escola: problemas da convivência potencializado pela pandemia?" DOI: 10.51359/2448-0215.2021.250506 
promoção da convivência. É por essa razão nossa insistência de que escolas, universidades e redes públicas ou particulares de ensino tenham políticas de formação de professores que possam discutir as ações de promoção da melhoria do clima relacional das escolas, antes que elas explodam.

O fato é que essas ações de prevenção aos problemas de convivência exigem tempo e esforço coletivo. Mas, não é o que, costumeiramente, fazemos. Scheinvar (2012) aponta que o encaminhamento de problemas de comportamento ocorridos na escola ao Conselho Tutelar é algo constante e corriqueiro. $\mathrm{O}$ autor enfatiza a busca por práticas punitivas e as queixas da escola a respeito da pouca efetividade do Conselho Tutelar, que "não pune suficientemente aqueles que não respeitam as convenções da escola". A mesma pesquisa enfatiza a frustração dos conselheiros que não conseguem resolver o problema e reclamam da leviandade da regra convencional que é cobrada pela escola.

Em uma pesquisa atual, Fernandes e Aragão (2011) também põem em cheque os encaminhamentos das escolas ao Conselho Tutelar. Rebeldia, indisciplina, briga entre alunos e entre professores seriam problemas de competência deste órgão? Estamos certos de que a resposta a esta pergunta é negativa. Contudo, são relatos da realidade vivida em muitas redes de ensino no país e que mostram o quanto a escola pouco sabe como atuar nos problemas de convivência que assolam a instituição. Como dizem as autoras desta investigação, demandas comuns são patologizadas e mostram o quanto há um longo caminho para a construção de uma Rede de Proteção que possa reconhecer e atuar de forma a garantir o que é de sua responsabilidade. Mais um exemplo disso são os registros de Boletins de Ocorrências realizados pelas escolas: comportamentos inadequados ou problemas de indisciplina são, frequentemente, entendidos como “casos de polícia” (FERREIRA, 2015). Por certo, há uma concepção de que a violência na escola deve ser tratada da mesma forma como a violência social. Eis um erro grosseiro e ingênuo, para não dizer, negligente: a escola não é a sociedade. A escola é uma instituição cuja responsabilidade é a formação das gerações mais novas que (ainda) podem não saber como viver em sociedade. Na sociedade, as regras estão postas pela necessidade de regulação da convivência para que direitos e deveres dos cidadãos sejam assegurados. Contudo, na escola, em formação, meninos e meninas precisam de espaços de construção e participação dessas regras. Precisam de espaços de reparação dos problemas que causam em suas relações com os outros. Judicializar ou criminalizar crianças e

Revista Tópicos Educacionais, Pernambuco, v. 27, n. 01, p. 62-78, 2021. ISSN: 2448-0215. https://periodicos.ufpe.br/revistas/topicoseducacionais/index Dossiê "Conflitos, violências, bullying na escola: problemas da convivência potencializado pela pandemia?" DOI: $10.51359 / 2448-0215.2021 .250506$ 


\section{Revista Tópicos Educacionais}

adolescentes ao invés de formar, é pouco compreender a função humanizadora das instituições que educam.

O fato é que os exemplos e dados de investigações apresentados até aqui mostram, no mínimo, a urgência da formação dos profissionais que atuarão no contexto pós-pandêmico. Do ponto de vista da lei, o Art. 70 do ECA aponta a importância de momentos de formação com os profissionais das referidas redes de proteção. Do ponto de vista da Psicologia e da Educação, o cuidado e a proteção de meninos e meninas é muito mais do que um cuidado instintivo que qualquer mãe ou pai deveria desenvolver. Em escolas e em serviços de assistência ou especialidades, quem atua são profissionais cujas ações não podem ser baseadas em senso comum. É verdade que, até certo tempo, as investigações nas diferentes ciências pouco se aproximavam da atuação desses profissionais. A ausência da temática da convivência e do desenvolvimento moral (que deve caracterizar as relações justas, respeitosas, tolerantes ou generosas entre as pessoas) nos currículos universitários e na formação continuada daqueles que estão à frente desses organismos de formação de crianças e adolescentes já fora sentida e reconhecida como um dos grandes nós que persistem em existir.

Aliás, o negacionismo científico tem sido, desgraçadamente, um mal entre nós brasileiros, o que dificulta ainda mais que entendamos o valor das discussões e reflexões democráticas que partam de conhecimentos e investigações das ciências, principalmente das ciências humanas tão desgastadas e desprezadas no atual governo deste país. E como vimos, não é apenas a escola que precisa formar seus profissionais. Pesquisas indicam a importância da formação para outros atores da rede (SILVA, ALBERTO, 2019). Educadores sociais, psicólogos, assistentes sociais e outros profissionais ainda apresentam falas que culpabilizam crianças e adolescentes por seus comportamentos e buscam, de forma equivocada, por meio do encaminhamento ao Conselho Tutelar e outros órgãos de defesa, como as delegacias, a punição para aqueles que deveriam ser cuidados e ensinados a reparar seus erros.

Ainda hoje, 31 anos após a promulgação do ECA, adolescentes brancos são chamados "adolescentes", enquanto parte da população se refere aos adolescentes negros como "menores". As questões estruturais vivenciadas em nossa sociedade a respeito da classe social, da raça e do gênero envolvem mais do que uma simples mudança na nomenclatura.

Assim, a formação destes profissionais diante dos problemas de convivência sobre temáticas como o uso de linguagem assertiva, o reconhecimento dos sentimentos e a mediação de

Revista Tópicos Educacionais, Pernambuco, v. 27, n. 01, p. 62-78, 2021. ISSN: 2448-0215. https://periodicos.ufpe.br/revistas/topicoseducacionais/index Dossiê "Conflitos, violências, bullying na escola: problemas da convivência potencializado pela pandemia?" DOI: $10.51359 / 2448-0215.2021 .250506$ 
conflitos, visando ao desenvolvimento da autonomia moral torna-se também essencial. Além do mais, o diálogo entre os serviços visando ao trabalho em rede, a discussão dos casos atendidos, a elaboração e reformulação de fluxos para melhor atender crianças e adolescentes é fundamental. Ouvir uma criança relatando um abuso sexual, compreender as dinâmicas familiares que impedem que uma mãe, também vítima de violência doméstica, proteja seus filhos das violências do companheiro, ser empático e ouvir os problemas que envolvem o público alvo do trabalho sem julgamento nem sempre é fácil e demanda conhecimento científico, formação técnica, ética e responsabilidade profissional.

Isto posto, diante da pandemia e da sua tão esperada superação, é preciso gastar tempo de estudo e de preparação para sabermos como lidar com tantos problemas que já começam a explodir nas escolas e famílias. O cenário não é promissor: por um lado, crianças e adolescentes, fadados ao isolamento, vitimizados pela violência ou negligência, precisarão de muitos colos para serem acolhidos. Por outro, professores, sufocados pelas exigências de mostrarem avanços nas avaliações institucionais para cumprirem as lacunas deste longo período de ausência das aulas, poderão se esquecer que a acolhida, a escuta, o cuidado serão as maiores necessidades para aqueles que logo manifestarão suas mazelas: as automutilações, os pensamentos suicidas, a violência (psicológica, verbal, sexual) contra o outro presencial e o outro virtual (os linchamentos virtuais, discursos de ódio, cancelamentos na internet).

O que nos resta fazer com os nós que ainda não conseguimos desatar é, portanto, investir em quem pode, num momento de escuridão com tamanho obscurantismo, trazer luzes a este cenário: é a Ciência, a marca da civilidade e da evolução do pensamento humano que nas crises nos expande e nos mostra o caminho mais oportuno recordando os marcos civilizatórios já aprendidos. Só a ciência, seja na Saúde, pelas formas mais elaboradas de vacinas capazes de vencer as novas cepas do coronavírus, seja na Educação, nas formas mais humanas e eficientes de cuidar de aspectos afetivos, tão urgentes neste momento, será capaz de, aos poucos, transformar os nós que nos prendem, em laços que humanizam.

\section{REFERÊNCIAS BIBLIOGRÁFICAS:}

Revista Tópicos Educacionais, Pernambuco, v. 27, n. 01, p. 62-78, 2021. ISSN: 2448-0215. https://periodicos.ufpe.br/revistas/topicoseducacionais/index Dossiê "Conflitos, violências, bullying na escola: problemas da convivência potencializado pela pandemia?" DOI: $10.51359 / 2448-0215.2021 .250506$ 
ARENDT, Hannah. Karl Marx y la tradición del pensamiento político occidental seguido de Reflexiones sobre la Revolución húngara. Presentación y edición de Agustín Serrano de Haro. Trad. Marina López e Agustín Serrano de Haro. Madrid: Encuentro, 2007.

BARROS, Marilisa Berti de Azevedo, et al. Relato de tristeza/depressão, nervosismo/ansiedade e problemas de sono na população adulta brasileira durante a pandemia de COVID-19.

Epidemiologia e Serviços de Saúde [online]. v. 29, n. 4. 2020. Disponível em https://www.scielo.br/scielo.php?pid=S2237-96222020000400311\&script $=$ sci arttext. Acesso 30 abr. 2021.

BAUMAN, Zygmunt. Modernidade Líquida. Rio de Janeiro: Jorge Zahar, 2001.

BRASIL. Lei 8.069 de 13 de julho de 1990. Estatuto da criança e do adolescente. Disponível em http://www.planalto.gov.br/ccivil 03/leis/18069.htm. Acesso 26 abr. 2020.

BRASIL. Lei 9.394 de 20 de dezembro de 1996. Estabelece as diretrizes e bases da educação nacional. Disponível em http://www.planalto.gov.br/ccivil_03/leis/19394.htm. Acesso 30 abr 2021.

BRASIL. Lei 13.010 de 26 de junho de 2014. Altera a Lei ${ }^{\circ} 8.069$, de 13 de julho de 1990 para estabelecer o direito da criança e do adolescente de serem educados e cuidados sem o uso de castigos físicos ou de tratamento cruel ou degradante, e altera a Lei $\mathrm{n}^{\circ}$ 9.394, de 20 de dezembro de 1996. Disponível em http://www.planalto.gov.br/ccivil 03/ ato2011-2014/2014/lei/113010.htm. Acesso 30 abr. 2021.

BRASIL. Lei 13.185 de 6 de novembro de 2015. Institui o Programa de Combate à Intimidação Sistemática (Bullying). Disponível em http://www.planalto.gov.br/ccivil 03/ ato20152018/2015/lei/113185.htm. Acesso 30 abr 2021.

BRASIL. Lei 13.431 de 4 de abril de 2017. Estabelece o sistema de garantia de direitos da criança e do adolescente vítima ou testemunha de violência. Disponível em http:/www.planalto.gov.br/ccivil_03/ ato2015-2018/2017/lei/113431.htm. Acesso 02 jul. 2020.

BRASIL. Disque Direitos Humanos. Relatório 2019. Disponível em https://www.gov.br/mdh/ptbr/ondh/acesso-a-informacao/dados-abertos/disque100/relatorios. Acesso em 15 abr 2021.

DALLARI, Dalmo de Abreu; KORCZAK, Janusz. O direito da criança ao respeito. Summus, 1986.

Declaração dos Direitos da Criança. 1959. Disponível em http://www.direitoshumanos.usp.br/index.php/Crian\%C3\%A7a/declaracao-dos-direitos-dacrianca.html. Acesso 30 abr 2021.

FERNANDES, Priscila Valverde; ARAGAO, Elizabeth Maria Andrade. Peculiaridades entre Conselho Tutelar e crianças encaminhadas pela escola. Fractal: Revista de Psicologia, v. 23 - n. 1, p. 219-232, Jan./Abr. 2011. Disponível em https://www.scielo.br/scielo.php?pid=S1984-

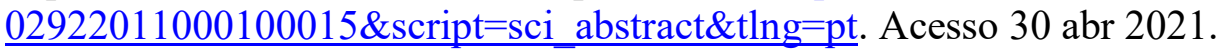

Revista Tópicos Educacionais, Pernambuco, v. 27, n. 01, p. 62-78, 2021. ISSN: 2448-0215. https://periodicos.ufpe.br/revistas/topicoseducacionais/index Dossiê "Conflitos, violências, bullying na escola: problemas da convivência potencializado pela pandemia?" DOI: $10.51359 / 2448-0215.2021 .250506$ 
FERREIRA, Pâmela Cristiane Gomes. Do boletim escolar ao boletim de ocorrência: o que está acontecendo com as escolas? Dissertação de mestrado pela Universidade Federal de Rondônia - UNIR. Porto Velho, Rondônia, 2015. 138f.

FUNDAÇÃO ABRINQ. Cenário da infância e da adolescência no Brasil 2021. Fundação Abrinq, 1 ed, 2021. Disponível em https:/www.fadc.org.br/sites/default/files/2020-03/cenariobrasil-2020-1aedicao.pdf. Acesso 30 abr 2021.

LEVANDOWSKI, Mateus Luz, et al. Impacto do distanciamento social nas notificações de violência contra crianças e adolescentes no Rio Grande do Sul, Brasil. Cad. Saúde Pública, Rio de Janeiro, v. 37, n. 1, e00140020, 2021. Disponível em http://www.scielo.br/scielo.php?script=sci arttext\&pid=S0102311X2021000105001\&lng=pt\&nrm=iso. Acesso em 16 mar. 2021.

PEREIRA, Karine Yanne de Lima; TEIXEIRA, Solange Maria. Redes e intersetorialidade nas políticas sociais: reflexões sobre sua concepção na política de assistência social. Textos \& Contextos (Porto Alegre), v. 12, n. 1, p. 114 - 127, jan./jun. 2013.

PLATT, Vanessa Borges; GUEDERT, Jucélia Maria; COELHO, Elza Berger Salema. Violence against children and adolescents: notification and alert in times of pandemic. Rev. paul. pediatr., São Paulo, v. 39, e2020267, 2021. Disponível em http://www.scielo.br/scielo.php?script=sci arttext\&pid=S010305822021000100434\&lng=en\&nrm=iso. Acesso em 08 Fev. 2021.

SCHEINVAR, Estela. Conselho tutelar e escola: a potência da lógica penal no fazer cotidiano. Psicologia \& Sociedade, 24, 45-51. 2012. ISSN 1807-0310. https://doi.org/10.1590/S010271822012000400008 .

SILVA, Ana Cristina Serafim; ALBERTO, Maria de Fátima Pereira. Fios soltos na rede de proteção dos direitos das crianças e adolescentes. Psicologia: Ciência e Profissão, 2019, v. 39, e185358, 1-13. https://doi.org/10.1590/1982-3703003185358.

The Alliance for Child Protection in Humanitarian Action, End Violence Against Children, UNICEF, WHO, COVID-19: Protecting Children from Violence, Abuse and Neglect in the Home, Version 1, May 2020. Disponível em https://www.alliancecpha.org/en/child-protectiononline-library/covid-19-protecting-children-violence-abuse-and-neglect-home. Acesso em 08 de fev 2021.

Recebido em maio de 2021. Aprovado em junho de 2021.

Revista Tópicos Educacionais, Pernambuco, v. 27, n. 01, p. 62-78, 2021. ISSN: 2448-0215. https://periodicos.ufpe.br/revistas/topicoseducacionais/index Dossiê "Conflitos, violências, bullying na escola: problemas da convivência potencializado pela pandemia?" DOI: $10.51359 / 2448-0215.2021 .250506$ 